Editorial

\section{A New Adventure for our Journal!}

\author{
Giuseppe Milano ${ }^{1}$ \\ ${ }^{1}$ Department of Orthopaedics, Service of Shoulder Surgery, \\ A. Gemelli University Hospital, Rome, Italy
}

Joints 2017;5:1.

A journal editor writing an editorial, or indeed anyone else entrusted with this task, is usually expected to draw attention to the highlights of the current issue (new developments, debated issues, controversial opinions, and so on), thereby giving an idea of the potential impact of its content on readers and on the broader scientific community.

It is therefore hardly surprising that I am opening this editorial, the first of the year, with news of the most important and obvious new development concerning Joints: we have changed publishers!

With the first issue of 2017, Joints has switched from CIC Edizioni Internazionali to Thieme Medical Publishers, a major publishing house that is well established in the field of international medical literature and boasts a catalog of successful journals, also in the area of orthopedics. Joints is now pleased to be joining these lists of journals. Our journal will be maintaining its particular areas of interest and the editorial philosophy it has always followed-highly inclusive and geared at supporting authors. As you will find, many formal aspects have changed (e.g., the graphics, the peerreview platform, and the editorial workflow support), but the driving spirit of the journal and its original mission, which, as I have said before, is captured by its very name, will remain unchanged.

I feel sure that this new development will boost the enthusiasm of the people that already work for Joints, in particular, the reviewers and editorial board members. At the same time, our regular readers will undoubtedly be intrigued by their journal's new editorial format, while new readers will probably be drawn to Joints partly because of this new development.
As we embark on this new adventure with a great sense of enthusiasm and anticipation, I nevertheless feel that we owe a debt of gratitude to CIC Edizioni Internazionali and its editorial team members, on whose support we counted throughout the first 4 years of this journal's life. Therefore, on behalf of the entire editorial board of the journal and the governing board of SIGASCOT, of which Joints has always been the official organ, as well as the authors and readers who have supported our work in recent years, I wish to extend our sincere thanks to them all. With the input and support of our previous publisher, we founded this journal and gave it a visual identity, implemented a dedicated workflow process, and carefully nurtured every aspect of its growth, in both form and content. In this way we succeeded, very quickly, in getting Joints indexed on PubMed and other databases, thus allowing it to achieve greater international visibility. On this basis, we were able to approach a large publisher, Thieme, with a product that was valid and reliable regarding content and regularity of publication. For this, then, we wish to express our thanks, once again, to CIC Edizioni Internazionali, with which we retain links through other scientific and editorial projects.

In conclusion, Joints continues to be a "multitasking" publication that covers a range of different article types (original articles, systematic and narrative reviews, technical notes, and case reports), levels of evidence, scientific fields and topics. I am confident that this first issue of 2017 will have something for all our readers, whatever their particular interests, which may be the hip, the knee or the ankle, and which also range from basic science in animal models to clinical studies with a high level of evidence, and from regenerative medicine to prosthetic surgery.
Address for correspondence Giuseppe Milano, MD, Department of Orthopaedics, Service of Shoulder Surgery, A. Gemelli University Hospital, Largo Agostino Gemelli, 00136, Rome, Italy (e-mail: giuseppe. milano@unicatt.it).
DOI http://dx.doi.org/ $10.1055 / \mathrm{s}-0037-1601480$. ISSN 2282-4324.
Copyright @ 2017 Georg Thieme Verlag KG Stuttgart · New York
License terms

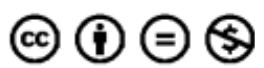

